\title{
Longitudinal Follow-Up on the Growth Rates and Influence Factors of Preterm and Full-Term Infants in Urban Areas of Hubei Province: A Birth Cohort Study
}

\author{
Zhonggui Xiong ( $\nabla$ xiongzhonggui@hbfy.com ) \\ Maternal and Child Health Hospital of Hubei Province \\ Feimin Sun \\ Wuhan University of Science and Technology \\ Zeyuan Xia \\ Wuhan University of Science and Technology
}

\section{Research Article}

Keywords: infant, length, weight, growth rate, longitudinal study

Posted Date: January 3rd, 2022

DOI: https://doi.org/10.21203/rs.3.rs-1214075/v1

License: (c) (1) This work is licensed under a Creative Commons Attribution 4.0 International License.

Read Full License 


\section{Abstract}

Objective: It was to explore the growth rates and influence factors of length and weight of preterm and full-term infants in urban areas of Hubei province to provide reference for child health and related clinical field.

Methods: A birth cohort study was used to analyze the growth rates and influence factors of length and weight of preterm and full-term infants in urban areas of Hubei province by multivariate regression analysis.

Results: The growth rates of length and weight of preterm infants were significantly lower than those of full-term infants from birth to 3 months $(P<0.05)$, and gradually caught up to the level of full-term infants after 3 months $(P>0.05)$. Meanwhile, there were some influence factors which had significant differences by the contribution to the growth rates of length and weight of preterm and full-term infants. It was proposed that the perinatal factors were attached more importance to the growth rates of preterm infants.

Conclusion: This study was to investigate the growth rates and influence factors of length and weight of preterm and full-term infants, and to take effective intervention measures to promote growth and development of preterm infants in urban areas of Hubei province.

\section{Introduction}

Longitudinal follow-up of infant growth rates is to conduct regular physical measurement to screen highrisk infants who deviate from the normal trajectory of growth and development. A comprehensive understanding of optimal postnatal growth is of critical importance for improving survival and long-term outcomes in preterm and full-term infants $[1,2]$.

Many international studies have shown that the infant growth rates are a nonlinear and significant variation which is a series of alternating processes of rapid growth and stagnation. Based on the global multicenter study, the World Health Organization (WHO) collected a large sample of the longitudinal data of children from 0 to 24 months and the cross-sectional data of children from 18 to 60 months to establish the international parameters of the ideal growth rates in 2006 [3]. Subsequently, the National Center for Women and Children's Health (China WCH) collected a large sample of the longitudinal data of children from 0 to 36 months to establish the national references of the growth rates in 2010 .

However, the growth pattern of preterm infants is significantly different from that of full-term infants at different ages [4]. In study design, some previous studies mainly adopted the cross-sectional investigation which was not suitable for exploring the growth rates of preterm and full-term infants. Unfortunately, the longitudinal follow-up was seldom used to determine the growth rates and influence factors of preterm and full-term infants. Hence, the dramatic effects of the perinatal factors on the growth 
rate of preterm and full-term infants should be thoroughly considered for prevention of growth retardations and late complications.

Therefore, we have constructed the longitudinal data from a specific birth cohort of singleton preterm and full-term infants during the first year of life. Based on the longitudinal data, this study was to explore the growth rates and influence factors of length and weight of preterm and full-term infants, and take effective intervention measures to promote infant growth and development in urban areas of Hubei province.

\section{Material And Methods Study subjects}

The subjects in this study, a total of 198 paired preterm and full-term infants (102 boys and 96 girls), were enrolled in Maternal and Child Health Hospital of Hubei Province, Jingzhou City, and Shiyan City during Jan 2019 to Jun 2020. All the subjects were Han Chinese in urban areas of Hubei province. Hence, a birth cohort study was used in this scientific design. The matching conditions were set as preterm and fullterm infants with the same gender, the same age (no more than \pm 7 days), the same residential community, and the same healthy status.

In this study, inclusion criteria were singleton live births of preterm infants with gestational age of $24^{+0}$ to $36^{+6}$ weeks in the case group, and full-term infants with gestational age of $37^{+0}$ to $42^{+6}$ weeks in the control group. Meanwhile, exclusion criteria were as follows: (1) twin or multiple; (2) assisted reproduction; (3) severe congenital malformations and genetic metabolic diseases at birth; (4) foreigners whose parents were non-Chinese; (5) maternal height $<145 \mathrm{~cm}$; (6) maternal age < 18 years or > 40 years; (7) mothers sustained smoking, alcoholism and/or drug dependence during pregnancy; (8) mothers have taken some adrenocortical hormones or other immunosuppressants continuously for more than one month during pregnancy; (9) mothers had severe anemia (hemoglobin less than $60 \mathrm{~g} / \mathrm{L}$ ), diabetes, preeclampsia, eclampsia, hyperthyroidism or hypothyroidism, heart and kidney insufficiency, or chronic hypertension during pregnancy.

\section{Clinical observation}

The data of longitudinal follow-up were regularly collected from routine health visits for preterm and fullterm infants. Child health physicians or pediatricians who have conducted professional training regularly monitored length and weight of preterm and full-term infants at birth, 1, 3, 6, 9, and 12 months by means of the standard method of physical measurement. During the follow-up period, there were 6 monitoring times in total: the first monitoring time was conducted within 24 hours after birth (completed by provincial and municipal delivery institutions), and the other monitoring times were conducted at the corresponding points of physical measurements (completed by provincial and municipal maternal and child health institutions). Length and weight of preterm and full-term infants were measured in a supine position by using a height/weight measuring appliance (Kangwa, Wuhan, China; length range 30-105 cm 
with digit counter readings precise to $0.1 \mathrm{~cm}$, and weight range $0-60 \mathrm{~kg}$ with digit counter readings precise to $0.01 \mathrm{~kg}$ ). Finally, length and weight of preterm and full-term infants were taken as the average values of 2 physical measurements.

\section{Epidemiological investigation}

The data of influence factors were also regularly collected from routine health visits for preterm and fullterm infants. Child health physicians or pediatricians who have conducted professional training investigated infant parents or guardians about the influence factors of preterm and full-term infants by the aid of a self-designed questionnaire. The survey contents of the influence factors were as follows: (1) general demographic data such as infant name, gender, and age; (2) parental height, occupation, education level, family upbringing mode, environmental structure, economic status, and other family conditions; (3) maternal smoking, drinking, drug dependence, assisted reproduction, gestational weeks, delivery pattern, and other perinatal conditions during pregnancy; (4) infant birth length, birth weight, Apgar score, feeding pattern, supplementary food addition, and other nutritional conditions;(5)infant previous health status and family disease history.

\section{Quality control}

Strict quality control was adopted in accordance with the implementation plan of this study. The survey methods of quality control were as follows: (1) the height/weight measuring appliance was inspected annually according to the national standard, and professional evaluation and verification were conducted before the clinical observation of height and weight of preterm and full-term infants; (2) two investigators measured each infant twice in line with the standardized method of physical measurement. The length error of 2 measurements was no more than $0.1 \mathrm{~cm}$, and the weight error of 2 measurements was no more than $0.01 \mathrm{~kg}$. The third measurement was carried out if the length and weight errors of 2 measurements exceeded the allowable range. Finally, only 2 measurements were recorded in a registration form if the length and weight errors of the corresponding measurements were within the allowable range; (3) the project technical guidance group regularly conducted on-site supervision and inspection to evaluate the standard method of physical measurement; (4) all investigation cards were subject to preliminary review and reexamination. Only investigation cards which were confirmed to be correct could be regarded as the qualified cards; (5) the lost follow-up rate of all the subjects was controlled within $10 \%$.

\section{Ethics statement}

This study was conducted in accordance with the related guidelines of the Declaration of Helsinki. The study protocol was approved by the Ethical Committee of Maternal and Child Health Hospital of Hubei Province. Meanwhile, informed written consent was obtained from all the parents or their guardians of preterm and full-term infants.

\section{Statistical analysis}

Epidata 4.4 (Epidata Association, Odense, Denmark) was used to establish the related database, and SPSS 20.0 (IBM Corp., Armonk, New York, America) was used to conduct the logic check and statistical 
analysis. The growth rates of preterm and full-term infants accorded with the quantitative data of normal distribution. Meanwhile, the growth rates of preterm and full-term infants were expressed by the increase of absolute values of 2 adjacent ages, and the differences of the growth rates were expressed by the mean and $95 \%$ confidence interval $(95 \% \mathrm{Cl})$ between preterm and full-term infants. Based on the descriptive analysis, 1:1 paired t-test was conducted for the mean between preterm and full-term infants, and the significance test level was set as $\mathrm{P}<0.05$. Furthermore, Taking y (length or weight) as dependent variable, and $x_{i}$ as independent variables, multivariate regression analysis was conducted for the influence factors between preterm and full-term infants, and the significance test level was set as $\mathrm{P}<$ 0.05 .

\section{Results}

\section{Baseline characteristics}

Of 216 study subjects ( 110 boys and 106 girls), the lost preterm and full-term infants were 18 ( 8 boys and 10 girls), and the missing follow-up rate was $8.33 \%$ in the longitudinal follow-up study.

\section{Growth rate of length}

The growth rate of length of preterm infants was significantly lower than that of full-term infants from birth to 3 months $(P<0.05)$. With the increase of age, there was no significant difference in the growth rate of length between preterm and full-term infants from 3 to 12 months $(P>0.05)$. It was suggested that length of preterm infants appeared catch-up growth after 3 months, and gradually reached the level of full-term infants as shown in Table 1 and 2.

Table 1

The growth rate of male infants by age-specific length $(\mathrm{cm})$

\begin{tabular}{|c|c|c|c|c|c|c|}
\hline \multirow[t]{2}{*}{ Age (Month) } & \multicolumn{2}{|c|}{ The growth rate $(\mathrm{cm})$} & \multirow[t]{2}{*}{ Difference $(95 \% \mathrm{Cl})$} & \multirow[t]{2}{*}{ SD } & \multirow[t]{2}{*}{$t$} & \multirow[t]{2}{*}{$\mathbf{P}$} \\
\hline & preterm & full-term & & & & \\
\hline Birth & 3.61 & 4.95 & $-1.34(-1.71,-0.97)$ & 0.37 & 3.585 & $<0.01$ \\
\hline 1区 & 6.44 & 7.44 & $-1.00(-1.45,-0.55)$ & 0.45 & 2.246 & $<0.05$ \\
\hline $3 \rrbracket$ & 5.95 & 6.44 & $-0.49(-0.83,-0.15)$ & 0.34 & 1.444 & $>0.05$ \\
\hline 60 & 3.89 & 4.26 & $-0.37(-0.62,-0.12)$ & 0.25 & 1.516 & $>0.05$ \\
\hline $9 \bigotimes 12$ & 3.35 & 3.56 & $-0.21(-0.54,0.12)$ & 0.33 & 0.626 & $>0.05$ \\
\hline
\end{tabular}

The growth rate: the length increase of absolute values of 2 adjacent ages. Difference: the growth rate of length of preterm minus full-term infants. $95 \% \mathrm{Cl}$ : $95 \%$ confidence interval. SD: standard deviation. 
Table 2

The growth rate of female infants by age-specific length $(\mathrm{cm})$

\begin{tabular}{|c|c|c|c|c|c|c|}
\hline \multirow{2}{*}{$\begin{array}{l}\text { Age } \\
\text { (Month) }\end{array}$} & \multicolumn{2}{|c|}{ The growth rate $(\mathrm{cm})$} & \multirow[t]{2}{*}{ Difference $(95 \% \mathrm{Cl})$} & \multirow[t]{2}{*}{ SD } & \multirow[t]{2}{*}{$t$} & \multirow[t]{2}{*}{$\mathbf{P}$} \\
\hline & preterm & full-term & & & & \\
\hline Birth $\square$ & 3.51 & 4.78 & $-1.27(-1.62,-0.92)$ & 0.35 & 2.914 & $<0.01$ \\
\hline 1区 & 5.72 & 6.68 & $-0.96(-1.34,-0.58)$ & 0.38 & 2.379 & $<0.05$ \\
\hline $3 \rrbracket$ & 5.76 & 6.22 & $-0.46(-0.79,-0.13)$ & 0.33 & 1.770 & $>0.05$ \\
\hline $6 \rrbracket$ & 3.89 & 4.25 & $-0.36(-0.57,-0.15)$ & 0.21 & 1.142 & $>0.05$ \\
\hline $9 \bigotimes 12$ & 3.65 & 3.86 & $-0.21(-0.53,0.11)$ & 0.32 & 0.428 & $>0.05$ \\
\hline
\end{tabular}

The growth rate: the length increase of absolute values of 2 adjacent ages. Difference: the growth rate of length of preterm minus full-term infants. $95 \% \mathrm{Cl}$ : $95 \%$ confidence interval. SD: standard deviation.

Growth rate of weight

The growth rate of weight of preterm infants was significantly lower than that of full-term infants from birth to 3 months $(P<0.05)$. With the increase of age, there was no significant difference in the growth rate of weight between preterm and full-term infants from 3 to 12 months $(P>0.05)$. It was suggested that weight of preterm infants developed catch-up growth after 3 months, gradually attained the level of full-term infants as shown in Table 3 and 4.

Table 3

The growth rate of male infants by age-specific weight $(\mathrm{kg})$

\begin{tabular}{|c|c|c|c|c|c|c|}
\hline \multirow[t]{2}{*}{ Age (Month) } & \multicolumn{2}{|c|}{ The growth rate $(\mathrm{kg})$} & \multirow[t]{2}{*}{ Difference $(95 \% \mathrm{Cl})$} & \multirow[t]{2}{*}{ SD } & \multirow[t]{2}{*}{$t$} & \multirow[t]{2}{*}{$\mathbf{P}$} \\
\hline & preterm & full-term & & & & \\
\hline Birth $\square$ & 1.05 & 1.32 & $-0.27(-1.00,0.46)$ & 0.73 & 3.704 & $<0.01$ \\
\hline 1区 & 1.86 & 2.38 & $-0.52(-1.39,0.35)$ & 0.87 & 2.389 & $<0.05$ \\
\hline 38 & 1.44 & 1.61 & $-0.17(-0.98,0.64)$ & 0.81 & 1.293 & $>0.05$ \\
\hline 68 & 0.79 & 0.99 & $-0.20(-1.19,0.79)$ & 0.99 & 1.230 & $>0.05$ \\
\hline 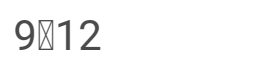 & 0.80 & 0.94 & $-0.14(-0.90,0.62)$ & 0.76 & 0.376 & $>0.05$ \\
\hline
\end{tabular}

The growth rate: the weight increase of absolute values of 2 adjacent ages. Difference: the growth rate of weight of preterm minus full-term infants. $95 \% \mathrm{Cl}$ : $95 \%$ confidence interval. SD: standard deviation. 
Table 4

The growth rate of female infants by age-specific weight $(\mathrm{kg})$

\begin{tabular}{|c|c|c|c|c|c|c|}
\hline \multirow[t]{2}{*}{ Age (Month) } & \multicolumn{2}{|c|}{ The growth rate $(\mathrm{kg})$} & \multirow[t]{2}{*}{ Difference $(95 \% \mathrm{Cl})$} & \multirow[t]{2}{*}{ SD } & \multirow[t]{2}{*}{$\mathrm{t}$} & \multirow[t]{2}{*}{$\mathbf{P}$} \\
\hline & preterm & full-term & & & & \\
\hline Birth $\square$ & 1.04 & 1.27 & $-0.23(-1.01,0.55)$ & 0.78 & 3.056 & $<0.01$ \\
\hline 1区 & 1.78 & 2.29 & $-0.51(-1.40,0.38)$ & 0.89 & 2.775 & $<0.05$ \\
\hline $3 \rrbracket$ & 1.41 & 1.58 & $-0.17(-1.00,0.66)$ & 0.83 & 2.365 & $>0.05$ \\
\hline 68 & 0.68 & 0.88 & $-0.20(-1.05,0.65)$ & 0.85 & 1.884 & $>0.05$ \\
\hline $9 \bigotimes 12$ & 0.71 & 0.84 & $-0.13(-0.75,0.49)$ & 0.62 & 1.103 & $>0.05$ \\
\hline
\end{tabular}

The growth rate: the weight increase of absolute values of 2 adjacent ages. Difference: the growth rate of weight of preterm minus full-term infants. $95 \% \mathrm{Cl}$ : 95\% confidence interval. SD: standard deviation.

\section{Influence factors of the growth rate of length}

Taking y (length) as dependent variable and $x_{i}$ ( 5 factors) as independent variables, multivariate regression analysis was carried out under the condition of $a=0.05$. There were 2 positive variables of gestational weeks and birth length, and one negative variable of delivery times which had the significant differences by the contribution to the growth rate of length of preterm infants as demonstrated in Table 5 .

Table 5

Influence factors of the growth rate of infants by age-specific length $(\mathrm{cm})$

\begin{tabular}{|c|c|c|c|c|c|c|c|}
\hline \multirow[t]{2}{*}{ Model } & \multicolumn{2}{|c|}{$\begin{array}{l}\text { Non standardized } \\
\text { coefficient }\end{array}$} & $\begin{array}{l}\text { Standardized } \\
\text { coefficient }\end{array}$ & \multirow[t]{2}{*}{$t$} & \multirow[t]{2}{*}{$\mathbf{P}$} & \multicolumn{2}{|c|}{$\begin{array}{l}\text { Collinearity } \\
\text { statistics }\end{array}$} \\
\hline & B & SD & B & & & $\delta$ & VIF \\
\hline Constant & -7.361 & .624 & & -11.806 & .000 & & \\
\hline Group & -.113 & .037 & -101 & -3.031 & .003 & .870 & 1.150 \\
\hline $\begin{array}{l}\text { Delivery } \\
\text { times }\end{array}$ & -.069 & .036 & -.061 & -2.944 & .043 & .976 & 1.024 \\
\hline $\begin{array}{l}\text { Gestational } \\
\text { weeks }\end{array}$ & .064 & .013 & .210 & 4.893 & .000 & .522 & 1.915 \\
\hline Birth length & .167 & .012 & .636 & 13.898 & .000 & .462 & 2.166 \\
\hline
\end{tabular}

\section{Influence factors of the growth rate of weight}

Taking y (weight) as dependent variable and $x_{i}$ (5 factors) as independent variables, multivariate regression analysis was carried out under the condition of $a=0.05$. There were 2 positive variables of gestational week and birth weight, and 2 negative variables of delivery times and pregnancy-induced 
hypertension syndrome which had the significant differences by the contribution to the growth rate of weight of preterm infants as demonstrated in Table 6.

Table 6

Influence factors of the growth rate of infants by age-specific weight $(\mathrm{kg})$

\begin{tabular}{|c|c|c|c|c|c|c|c|}
\hline \multirow[t]{2}{*}{ Model } & \multirow{2}{*}{$\begin{array}{l}\text { Non } \\
\text { standardized } \\
\text { coefficient }\end{array}$} & \multicolumn{2}{|c|}{$\begin{array}{l}\text { Standardized } \\
\text { coefficient }\end{array}$} & \multirow[t]{2}{*}{$t$} & \multirow[t]{2}{*}{$\mathbf{P}$} & \multicolumn{2}{|c|}{$\begin{array}{l}\text { Collinearity } \\
\text { statistics }\end{array}$} \\
\hline & & SD & B & & & $\delta$ & VIF \\
\hline Constant & 35.315 & 1.950 & & 18.116 & .000 & & \\
\hline Group & -.249 & .140 & -.058 & -2.776 & .047 & .855 & 1.170 \\
\hline Delivery times & -1.103 & .417 & -.087 & -2.646 & .009 & .864 & 1.157 \\
\hline $\begin{array}{l}\text { Pregnancy-induced } \\
\text { hypertension } \\
\text { syndrome }\end{array}$ & -1.017 & .358 & -.088 & -2.841 & .005 & .965 & 1.036 \\
\hline Gestational weeks & .241 & .049 & .206 & 4.932 & .000 & .529 & 1.889 \\
\hline Birth weight & .002 & .000 & .615 & 14.216 & .000 & .495 & 2.022 \\
\hline
\end{tabular}

\section{Discussion}

In recent years, the life quality of preterm infants has been remarkably improved with continuous development of the healthy condition and close cooperation between obstetrics and pediatrics [5]. Relevant researches manifest that there is a vital "opportunity window" for the growth rates of preterm infants within 2 to 3 months of corrected age, which will play an extremely important role in future growth and development. According to the recommendation of the American Academy of Pediatrics (AAP), the physiological functions of various system organs of preterm infants are not mature enough after birth. The goal of the growth rates of preterm infants is to approach the growth rates of full-term infants at the first year of age. However, the growth rates of preterm infants are significantly different from those of fullterm infants since preterm infants are prone to cumulative malnutrition and growth restriction [6]. Therefore, continuously monitoring of the growth rates of preterm infants is a critical field in pediatric clinic and child health by utilizing the appropriate evaluation criteria $[7,8]$.

Most scholars convinced that birth length and birth weight were positively correlated with the growth rates of length and weight of preterm and full-term infants [9]. Birth length was the main indicator to monitor fetal linear growth, and it was closely related to infant growth retardation and even adult short stature. Meanwhile, birth weight was the common index to monitor fetal growth rate and recent nutritional status, and it was also correlated to infant growth rate and future health status [10]. The research results of Vieira et al. showed that the correlation between birth length and growth retardation or 
adult short stature of preterm infants was significantly higher than that of full-term infants. For example, the risk of adult short stature of preterm infants with birth length less than -2SD was 7 times higher than that of full-term infants. Simultaneously, the risk of adult short stature of preterm infants with birth weight less than -2SD was 4 times higher than that of full-term infants. In other words, it was suggested that birth length and birth weight could effectively identify the high-risk infants with growth retardation [11].

The growth trajectories of length and weight of preterm infants were obviously different from those of full-term infants from birth to 3 months [12]. This study showed that the growth rates of length and weight of preterm infants were significantly lower than those of full-term infants from birth to 3 months. Toftlund et al. also reported that the catch-up growth of preterm infants mainly occurred from birth to 3 months $[13,14]$. As for the catch-up growth, Miller et al. manifested that the advent of preterm formula or breast milk fortifier might be helpful in a more customized approach to the growth rates of preterm infants. Consequently, preterm infants could supplement additional calories in time, and present an obvious trend of catch-up growth [15]. Relevant studies further showed that some minerals such as zinc, copper, iron, and magnesium regulated heat metabolism through oxidative phosphorylation pathway, and additional heat could significantly promote the growth rate of preterm infants [16].

However, the growth trajectories of length and weight of preterm infants were rather close to those of fullterm infants after 3 months [17]. This study showed that the growth rates of length and weight of preterm infants gradually reached the level of full-term infants after 3 months. Arora 1 et al. reported that there was no significant difference in the growth rates between preterm and full-term infants after 3 months. It depended on continuous breastfeeding and timely addition of weaning food after 6 months. Therefore, Continuous breastfeeding and timely weaning food could effectively accelerate the growth rates, and control the potential risk of adult diseases in preterm infants $[18,19]$.

During the first year of age, there were significant differences in the growth rates of length and weight of preterm and full-term infants at different stages. The growth rates of preterm infants were significantly lower than those of full-term infants from birth to 3 months, and gradually caught up to the level of fullterm infants after 3 months [20]. Specifically, the growth rates of preterm and full-term infants were attributed to the regulatory mechanism of growth hormone (GH), insulin-like growth factor-1 (IGF-1), and insulin-like growth factor binding protein-3 (IGFBP-3). As for the regulatory mechanism, GH was an important regulator of the growth rates of preterm infants in a pulsed pattern, and IGF-1 formed a complex with IGFBP-3 which was closely related to the growth rates of preterm infants. Furthermore, Amina et al. reported that the serum levels of IGF-I and IGFBP-3 in preterm infants were lower than those in full-term infants $(P<0.001)$, and showed a dose-response relationship. Meanwhile, the serum levels of IGF-I and IGFBP-3 expressed the first secretion peak at 2 to 3 months, and then a slow downward trend in preterm infants [21].

Based on this study, the perinatal factors were attached more importance to the growth rates of preterm infants from birth to 3 months [22]. This study also manifested that there were some variables of birth 
length, birth weight, gestational weeks, delivery times, and pregnancy-induced hypertension syndrome which were the influence factors by the contribution to the growth rate of preterm infants. Zhang et al. revealed that the perinatal factors were related to the growth rates of preterm infants [23]. Besides gene polymorphisms, various perinatal factors jointly participated in the regulation mechanism of IGF-1 and IGFBP-3, and finally affected the growth rate of preterm infants [24]. Therefore, multidisciplinary interventions should be developed to promote the growth rates of preterm infants within the first 3 months.

There are some limitations to this study. First, we haven't recruited enough samples to unveil more risk factors of the growth rate of preterm infants due to the lost health visits at the corresponding points of physical measurement. Second, we haven't compared the growth rate of preterm and full-term infants in urban and suburb areas of Hubei province.

In a future study, we should establish a birth cohort study of the growth rates of preterm and full-term infants with increased duration of the physical follow-up, and detailed documentation of the potential factors. Furthermore, we should construct a multicenter study of the growth rates of preterm and full-term infants in a larger sample size stratified by gender and region.

\section{Conclusions}

In general, the infant growth rates are a nonlinear and significant variation which is a series of alternating processes of rapid growth and stagnation. This study showed that the growth rates of length and weight of preterm infants were significantly lower than those of full-term infants from birth to 3 months, and gradually caught up to the level of full-term infants after 3 months. Furthermore, there were some influence factors which had significant differences by the contribution to the growth rates of length and weight of preterm and full-term infants. It was proposed that the perinatal factors were paid more importance to the growth rates of preterm infants. Therefore, we should establish the growth model of length and weight of preterm infants, and take effective intervention measures to promote growth and development of preterm infants.

\section{Declarations}

\section{Conflict of interest}

No conflict of interest existed in the submission of this manuscript.

\section{Authors' contributions}

Zhonggui Xiong designed this project, and composed this paper for several times. Feimin Sunand Zeyuan Xia collected the clinical and epidemiological data for this paper for more than one year.

\section{Acknowledgement}


We thanked all the parents or guardians for their participation in this study, and we also thanked all the researchers for their work in the clinical observation and epidemiological investigation.

\section{References}

1. Embleton ND, Korada M, Wood CL, Pearce MS, Swamy R, Cheetham TD. Catch-up growth and metabolic outcomes in adolescents born preterm. Arch Dis Child, 2016, 101: 1026-1031. DOI: 10.1136/archdischild-2015-310190.

2. Ong KK, Kennedy K, Castaneda-Gutierrez E, Forsyth S, Godfrey KM, Koletzko B, Latulippe ME, Ozanne SE, Rueda R, Schoemaker MH, van der Beek EM, van Buuren S, Fewtrell M. Postnatal growth in preterm infants and later health outcomes: a systematic review. Acta Paediatr, 2015, 104(10): 974986. https://doi.org/10.1111/apa. 13128.

3. World Health Organization (WHO). The World Health Organization Child Growth Standards. 2006. Available online at: https://www.who.int/childgrowth/standards/en/ (accessed May 20, 2020).

4. Sankilampi U. One size may not fit all when it comes to growth references for preterm infants. Acta Paediatr, 2016, 105: 228-229. DOI: 10.1111/apa.13291.

5. Hoon LH, Kyu NO, Sil CY. Neonatal outcomes of very low birth weight infants in Korean neonatal network from 2013 to 2016. J Korean Med Sci, 2019, 34(5): e40.

6. Giuliani F, Cheikh Ismail L, Bertino E, Bhutta ZA, Ohuma EO, Rovelli I, Conde- Agudelo A, Villar J, Kennedy SH. Monitoring postnatal growth of preterm infants: present and future. Am J clin nutr, 2016, 103(2): 635S-647S. DOI:10.3945/ajcn.114. 106310.

7. Zhang L, Li Y, Liang S, Liu X, Kang F, Li G. Postnatal length and weight growth velocities according to Fenton reference and their associated perinatal factors in healthy late preterm infants during birth to term-corrected age: an observational study. Ital J Pediatr, 2019, 45(1): 1. DOI: 10.1186/s13052-0180596-4.

8. Rochow N, Landau-Crangle E, So HY, Pelc A, Fusch G, Dabritz J, Gopel W, Fusch C. Z-score differences based on cross-sectional growth charts do not reflect the growth rate of very low birth weight infants. PLoS ONE, 2019, 14(5): e0216048. https://doi.org/10.1371/journal.pone.0216048.

9. Kang L, Wang H, He C, Wang K, Miao L, Li Q, Wang Y, Zhu J, Liu X, Chen J, Chen Q, Mu D. Postnatal growth in preterm infants during the first year of life: a population-based cohort study in China. PLoS ONE, 2019, 14(4): e0213762. DOI: 10.1371/journal. pone.0213762.

10. Griffin IJ, Tancredi DJ, Bertino E, Lee HC, Profit J. Postnatal growth failure in very low birth weight infants born between 2005 and 2012. Arch Dis Child Fetal Neonatal Ed, 2016, 101(1): F50- F55. DOI: 10.1136/archdischild-2014-308095.

11. Vieira MC, Relph S, Persson M, Seed PT, Pasupathy D. Determination of birth-weight centile thresholds associated with adverse perinatal outcomes using population, customised, and intergrowth charts: A Swedish population-based cohort study. PLoS Med, 2019, 16(9): e1002902. DOI: 10.1371/journal.pmed.1002902. 
12. Fenton TR, Nasser R, Eliasziw M, Kim JH, Bilan D, Sauve R. Validating the weight gain of preterm infants between the reference growth curve of the fetus and the term infant. BMC Pediatr, 2013, 13: 92. DOI: 10.1186/1471-2431-13-92.

13. Toftlund LH, Halken S, Agertoft L, Zachariassen G. Catch-up growth, rapid weight growth, and continuous growth from birth to 6 years of age in very-preterm- born children. Neonatology, 2018, 114(4): 285-293. DOI: 10.1059/000489675.

14. Landau-Crangle E, Rochow N, Fenton TR, Liu K, Ali A, So HY, Fusch G, Marrin ML, Fusch C. Individualized postnatal prowth prajectories for preterm pnfants. JPEN J Parenter Enteral Nutr, 2018, 42(6): 1084-1092. DOI: 10.1002/jpen.1138.

15. Miller J, Makrides M, Gibson RA. Effect of increasing protein content of human milk fortifier on growth in preterm infants born at < 31 wk gestation: a randomized controlled trial. Am J Clin Nutr, 2012, 95: 648-655.

16. Nilsson A, Mardinoglu A, Neilsen J. Predicting growth of the healthy infant using a genome scale metabolic model. npi Syst Biol Appl, 2017, 3(3): 1-9. DOI: 10.1038/ s41540-017-0004-5.

17. Zhao Z, Ding M, Hu Z, Dai Q, Satija A, Zhou A, Xu Y, Zhang X, Hu F, Xu H. Trajectories of length, weight, and bone mineral density among preterm infants during the first 12 months of corrected age in China. BMC Pediatr, 2015, 15: 91. DOI: 10.1186/s12887-015-0396-6.

18. Arora1 A, Manohar N, Hector D, Bhole S, Hayen A, Eastwood J, Scott JA. Determinants for early introduction of complementary foods in Australian infants: findings from the HSHK birth cohort study. Nutrition J, 2020, 19(16): 1-10. https: //doi.org/10.1186/ s12937-020-0528-1.

19. de Beer M, Vrijkotte TGM, Fall CHD, van Eijsden M, Osmond C, Gemke RJBJ. Associations of infant feeding and timing of linear growth and relative weight gain during early life with childhood body composition. Int J Obesity, 2015, 39: 586-592. DOI: 10.1038/ijo.2014.200.

20. Zhang L, Lin J, Liang S, Sun J, Gao N, Wu Q, Zhang H, Liu H, Cheng X, Cao Y, Li Y. Comparison of postnatal growth charts of singleton preterm and term infants using World Health Organization standards at 40-160 Weeks postmenstrual age: a Chinese single-center retrospective cohort study. Front Pediatr, 2021, 9: 595882. DOI: 10.3389/fped.2021.59588.

21. Amina A, Abdelmoneim K, Nesma A, Soha Y. Correlation between insulin like growth factor-1 and anthropometric measurements of premature infants. J Nepal Paediatr Assoc, 2016, 36(1): 24.

22. Pizzi C, Cole TJ, Richiardi L, dos-Santos-Silva I, Corvalan C, De Stavola B. Prenatal influences on size, velocity and tempo of infant growth: findings from three contemporary cohorts. PLoS ONE, 2014, 9(2): e90291. https://doi.org/10.1371/ journal.pone.0090291.

23. Zhang T, Zhao L, Ding W, Ma J, Zhang Y. The influence of perinatal and maternal factors on physical growth at 12 months in prematurely born infants treated in the neonatal intensive care unit: $A$ retrospective chart review and a prospective cohort study. Int J Nurs Stud, 2020, 109: 103656. https://doi.org/10.1016/j.ijnurstu.2020. 103656.

24. Martin A, Connelly A, Bland RM, Reilly JJ. Health impact of catch-up growth in low-birth weight infants: systematic review, evidence appraisal, and meta-analysis. Matern Child Nutr, 2017, 13(1): 
e12297-e12310. DOI: 10.1111/mcn.12297.

Page $13 / 13$ 